\title{
Combination of image and spirituality in Odil Yakubov's novel "Old World"
}

\author{
Zaynutdinova Gulnoza \\ Master of Department of Methods of Teaching \\ Uzbek Language and Literature \\ Faculty of Uzbek Language and Literature \\ Tashkent State University of \\ Uzbek Language and Literature \\ Named after Alisher Navoi \\ Javohiraliyev26@mail.com
}

\begin{abstract}
This article examines in detail the imagery methods used in Odil Yakubov's novel "Old World”, such as portraits, landscapes, and battle scenes, and analyzes the author's effective use of these imagery techniques in illuminating artistic psychology. attitude.

Key words: Old world, image and spirit, portrait, landscape, war, space and time, artistic psychology, writer's
\end{abstract}

\section{I.Introduction}

The image changes dramatically with a person's life and his spiritual world. Sometimes a person changes depending on the image. When we say image, we don't just have to understand the landscape. Fiction includes images of space and time, images of war, images of people, portraits, and landscapes. Here are some of them: Odil Yakubov used these methods of depiction very effectively, all of which are very important in revealing the psychology of the work, the characters. First of all, if we talk about the image of nature, one of the ways to illuminate the image of the writer's soul is to convey the mood of the characters in all its complexity by depicting natural landscapes.

\section{II.Literature review}

In "Old world", landscapes are presented in several places, all of which serve to reveal the spirit of the character. In the eyes of a person who is in a good mood, healthy, and has no problems in his life, the environment is beautiful and unique, while in the eyes of a person who is not in a good mood, a person with a health problem, a person who is unlucky; the thing seems flawed. This is an ancient state of the human psyche. In this novel, we see the same thing in several places. Sultan Mahmud Ghaznavi was seriously ill, and Nadimi Abul Hasanak, who saw him frying in pain, organized a hunt around the Gardiz fortress. As the sultan lay in his chariot, he looked up at the sky and lamented that there was no cure for his ailment, not even the ruler of the time, Ibn Sina, and began to complain in this spirit. The author tries to reveal this situation in harmony with nature: "Why did God create this sky, this universe, this bird and the beast? For whom and for what purpose did you create this beauty?" These are the cries of a sick man who is deprived of nature in the face of the horrors of death. That is, he does not enjoy the beauty of nature. Because nothing fits in his heart, and the beauty of nature does not enlighten the heart of the sultan, who is dissatisfied with life. But things changed, and it was as if his father's fate would be repeated. In other words, chasing the lucky son, just like his father, signaled a bright future for him. After such a situation, the sultan looked at the environment and nature differently: "O repentance! The sky is clearer than the paint, the air is clearer than the paint, the smell of herbs - peppermint, snowdrop, mint by the spring, wild basil and spruce, the mixture of wormwood and thorn covering the surface of the hills is sharper than the paint, more fragrant than the paint! ". Apparently, a person's gaze depends on his mood. In a good mood, the sultan looks at nature in a special way.

\section{III.Analysis}

The fourth chapter of the work contains a description of nature through Beruni's gaze: "After a drizzle at night, the air is clear, the vegetation along the streams, the cotton walls, and even the grass on the roofs of the houses as green and clear as if they had been washed away." From these sentences it is clear that the character's mind is calm, still, and therefore appreciates nature. Turning to Beruni's view of the landscape, he said, "After the night rain, the garden was in full bloom, and the almonds and peaches, which were in full bloom everywhere, were just beginning to sprout among the apricots, apples, pears, and quinces, it is reminiscent of beautiful angels dressed in white, red, and pink." After a nightmare, Beruni's fever subsided, and when his condition improved, he went to the banks of the Afshan River to explore nature and search for beauty. Eventually, he begins to paint this landscape as if he were an artist. It is obvious that the author has a hand in these drawings, because no character can express the author's image in a bright and beautiful way. In addition, the author's related speech is used in several places in the work to describe nature, in which the author's speech can express not only the attitude to the psyche of the protagonists, but also his love for the outside world, nature: manifested with grace. "The fog on the hills has dissipated and the steppe is in full swing. There were sparse clouds in the sky, and the playful 
rays of the sun rising behind the hills kissed the dew on the leaves of the plants, bathed the whole steppe in a wonderful light, and the distant gardens shone brighter than ever. He is gone." This picture shows the author's passion for nature. In describing the steppe and its beauty, the author feels that nature is inconceivable without human beings, that they are inextricably linked.

In several other places in the work we find images of nature. That is, the third, fourth, seventh, ninth of the work will continue, and most of them will be depicted in accordance with the spirit of the character, and the rest will be in harmony with the place. The author used not only the image of nature, but also the portrait, the image of the place, the image of the battle in many parts of the work. In the character image, however, he acted very selectively. In the image of a positive protagonist, the author's relational speech is not very noticeable, it is just a line. But in the depiction of the negative protagonist, the author's relational speech is also involved. For example, in the image of Piri Bukri, the author's attitude is also evident: The wine shuddered, and he thought, "Is it old again?" thought. " In this picture, Piri Bukri is compared to a black spider. This sentence is described by the author as similar to that of Malik ul-Sharab, but the meticulous reader can distinguish that this analogy is a parable that belongs only to the author. That is, the author's attitude toward the negative protagonist.

\section{IV.Discussion}

In the second chapter of the work, Beruni compares two women, in which we can see their vivid appearance through the elegant lines of the characters: "Rayhana's eyes are as blue and elongated as the spring sky. His face was as white as milk, and his hair, which was wavy on his shoulders, was as red as a cup of charcoal. Sadafbibi is dark-skinned, with a round face and dark eyebrows." The author describes the images and situations and expresses his personal attitude to them. Let us turn our attention to the image of Khatlibegim: "He is wearing the clothes of the living and the victors: a long black silk shirt and a black camisole with a slim waist, a long black anima with gold on his face, and beautiful black shoes with toes on his feet. A large gold ring with ruby eyes on the hennaed fingers, the lady stopped the race and bowed politely. " It is not difficult to observe the image and realize that the person being portrayed is, first of all, a woman and a member of the upper class, and in terms of character, she is a calm and high-spirited woman. The writer was able to give the reader the opportunity to characterize the characters with the help of these images. The lines are so smooth and so natural that they make the person in front of us look like. The portraits of Malikul Sharab and Sadafbibi in the novel are described by the author through his own eyes and attitude: "He is wearing a striped blue velvet shirt, a red silk anima on his head, and a blue sakhtiyon with a pointed tip on his feet. Foot-wear, the girl sang a song in an inaudible voice, worked with pleasure, wiped the dust off the cupboard, took one of the heavy books in red, blue, and yellow volumes, and began to turn the pages in amazement.

He would stop whining as he turned the pages, his round face would look surprised and amazed, and as he put the book back in place, he would start whistling again." In this portrait, the author's gaze and attitude are reflected in the "behavior of the current girl, who picks up the books, flips through them in amazement, and does her job with kindness." There is a positive attitude of the author in the image of Sadafbibi, but in the image of Khatlibegim, which I mentioned above, there is a negative attitude of the author from the image of her luxurious clothes to her jewelry. We can tell the author's relationship by the sharp contrast between the images. In addition, the sharp differences between the portrait of Meshkobchi and Imam Said in the play are factors that determine the changes in the author's inner attitude. The play depicts two great historical figures by the author in a very convincing way, and when we read this picture, we imagine that he saw people in real life. Beruni's description: "Beruni thought as he reached for his curly, thick beard. In the light of the candles on the shelf, his overgrown eyebrows, his elongated dark face, his bulging forehead protruding from under his cap, and his long snub-nosed face, his whole face looked very intense, after all. he was more like a warrior who has been refined in fierce battles than a world-famous scholar." So Beruni was a tall, dark-skinned, handsome man with eyebrows raised.

And again, these would mean that you have to spend for these processes. The writer also mastered the depiction of space, which also served as a means of illuminating the inner world of a particular character in the work. For example, the image of the Queen of Heaven: in the most secluded corner of the Queen's Palace there will be a secret corner of the sultan, the walls of which will be copied from the epic "Alfiya-Shalfiya", colorful pictures depicting the love of naked women and men and it was adorned with gold statues of naked idols taken from the palaces of the Indian padishahs." It is natural that this image gives rise to negative views about the sultan. In other words, this image shows that the sultan was a seductive, immoral ruler, which arouses the reader's negative perception of the hero. Mahmoud Ghaznavi's character is often portrayed in a variety of images. In the third chapter of the novel, another image catches our attention:

"The sultan's heart was pounding and he went inside. It was very quiet. There is no sound. There are blue, yellow, and white flags of the conquered lands on the four sides of the sanctuary! Defeated flags! The defeated soldiers wore gold and silver helmets, gold-plated armor, and shields. Next to them are curved swords with pearls and emeralds, leather bows, daggers with bone handles, long and short blades... These weapons, each of these gifts is a saga! His countless marches, his priceless epics about the tumultuous journeys of Sultan Mahmud Ghaznavi... Whichever of these spoils the sultan captures, the victorious battle comes to mind, man-man amirs, kalondimog governors, even shahanshahs are remembered. 
Ambassadors from all over the world, even from China and Greece, fall into a trance when they see these priceless spoils, these colorful flags. Here is a huge shield made of pure gold, encrusted with rubies, rubies and jewels. Next to him was a large armor made of delicate gold rings... A gift from the Kashmir padishah... This giant, with more than a thousand maids in his harem, rode a raging elephant on the royal square. He bravely entered the field, playing with his black eyebrow, without being hit by a rabid elephant. Neither the roar of the raging elephant nor the horror of the elephant could be heard! When the sultan whipped his black rope, which had jumped into the sky in fear, he attacked the war elephant, put his feet on the stirrup, and with one blow threw the king over the elephant's shoulder!'(Chapter 3, 61 -62pp). This image is embodied in an episode of memory in which the sultan's heart aches at the memory of his past successes, and at the end he remembers this history with great anguish from such an incurable disease. Such battle scenes in the play are often used to reveal the psyche of Sultan Mahmoud Ghaznavi, and we see that the past achievements of the sick man, instead of cheering him up, make him even more anxious. It is obvious that religion, faith, social justice is the main spiritual problem of a writer's work, and its main aesthetic principle is to tell the truth, to show life with complexity.

In the novel "Old world", O. Yakubov portrays the portraits of ordinary people, rather than the portraits of positive heroes, in one or two characters, but in a more perfect way. He created a series of full-fledged characters by depicting their appearance and inner world in a dialectical unity. In short, O. Yakubov describes both the negative qualities of positive heroes and the positive qualities of negative heroes in an objective way. In this example, we see another picture of nature. "Near dawn, the stars in the sky were dim, the apricots and apples in bloom in the garden swayed in the morning breeze, and the air was filled with the delicate scent of spring herbs" (Chapter 13, 186p).

\section{V.Conclusion}

In conclusion, it is no exaggeration to say that the harmony of image and spirit is the content of the whole work. The depiction of nature and man is a national, as well as universal, phenomenon in fiction. The genre of the work, the image of the characters, the landscape also play an important role in perfecting the form of the work.

\section{References:}

1. O. Yakubov, the novel "Old world". New Generation, 2015.

2. A.Kholmurodov. "Psychologism in the novels of Odil Yakubov". T., 1991.

3. Ginzburg L. On psychological prose. -L .: 1971.

4. Qurbonov T.J. O. Yakubov's mastery of portraiture. NDA. T., 1997.

5. Isayeva Sh.B. Ways of depicting the spirit of character in Uzbek historical novels. Tashkent-2001.

6. Zokirjon Rahimov. The Poetics of the Old World. Fergana Publishing House, 2005.

7. Karimov B. The alphabet of spirit. - Tashkent: G. Gulom Publishing House, 2016.

8. Umurov.X. Artistic psychologism and contemporary romance. - T .: Fan. 1983.

9. Turaev D. The problem of artistic thinking and skill in Uzbek novels. - Tashkent: University, 2001.

10. Mamajonov S. Style polishes. T., Literature and Art, 1992. 